\title{
Процессуальное дефинирование правовой глобализации
}

\author{
Макогон Б.В. \\ Белгородский государственный национальный исследовательский университет, \\ Россия, 308015, г. Белгород, ул. Победы, 85 \\ E-mail: makogon@bsu.edu.ru
}

\begin{abstract}
Аннотация. На основе анализа широкого круга как форменных, так и генезисных источников представлена актуализация авторской позиции по поводу дефинирования правовой глобализации как процесса в широкой и методологически опорной его трактовках, базирующаяся на факте доказанности существования феномена глобализации в различных его ипостасях. Логическая цепочка рассуждений автора носит рискоориентированный характер; как результат последовательно рассмотрены достаточные характеристики правового измерения глобализации и предложено соответствующее им определение, сформулированное по блочно-модульной системе. Автор жестко не связывает глобализацию с теми или иными историческими периодами, а также знаковыми событиями мирового и регионального масштабов. Соответственно, авторское дефинирование по заявленной проблематике демонстрирует универсальные свойства в сцепке с актуальностью сегодняшнего дня.
\end{abstract}

Ключевые слова: глобализация, глобализация права, правовая глобализация.

Для цитирования: Макогон Б.В. 2020. Процессуальное дефинирование правовой глобализации. NOMOTHETIKA: Философия. Социология. Право. 46 (3): 527-532. DOI 10.18413/2712-746X-202044-3-527-532

\section{Procedural definition of legal globalization}

\author{
Boris V. Makogon \\ Belgorod National Research University, \\ 85 Pobeda St, Belgorod, 308015, Russia \\ E-mail: makogon@bsu.edu.ru
}

\begin{abstract}
Based on the analysis of a wide range of both formal and Genesis sources, the article presents the actualization of the author's position on the definition of legal globalization as a process in its broad and methodological support interpretations, based on the fact that the existence of the phenomenon of globalization in its various guises is proved. The author's logical chain of reasoning is risk oriented; as a result, sufficient characteristics of the legal dimension of globalization are consistently considered, and the corresponding definition is proposed, formulated according to the block-modular system. The author does not strictly connect globalization with certain historical periods, as well as significant events of global and regional scale. Accordingly, the author's definition of the stated problem demonstrates universal properties in conjunction with the relevance of today.
\end{abstract}

Keywords: globalisation, globalisation of law, legal globalisation.

For citation: Makogon B.V. 2020. Procedural definition of legal globalization. NOMOTHETIKA: Philosophy. Sociology. Law series. 46 (3): 527-532 (in Russian). DOI 10.18413/2712-746X-202044-3-527-532 


\section{Введение}

Одним из направлений объективирования глобализации является ее правовое измерение. Учитывая признанно высокое влияние именно сильных нормативных тенденций на формирование внутригосударственных и международных правовых массивов, соответствующее взаимодействие можно упорядочить по блокам, в которых ведущую роль играет либо глобализация, когда такие процессы формируют и направляют юридические трансформации, либо право, опосредующее стремления управлять глобализацией с получением соответствующих дивидендов.

Позитивные, негативные, системные, хаусоориентированные, конвергенционные, дивергенционные лица глобализации логично воплощаются в праве в целом независимо от периода, что логично. Часто агрессивная экспансия так называемой «демократии», сформулированных принципов в сфере прав человека и сопряженных рисков [Kornyushkina et al., 2017], природоохраны [Новикова, Анисимов, 2008], обмена, сотрудничества, взаимопомощи и поддержки, рационализации везде и во всем - все это обрамлено правовым регулированием, поскольку объективное право является той формой, которая при известной силовой поддержке обладает апробированным инструментарием для упорядочивания связей для достижения целей в глобальной кооперации.

Конечно, не только тенденции глобализации проявляются в современном праве, но и само право глобализируется, что, вероятно, можно считать предметом (а кто-то, быть может, даже скажет: «...объектом») самостоятельной междисциплинарной дискуссии. Синтезируются принципы и нормы, провозглашаемые общепризнанными; покрываются туманом границы между правовыми семьями и правовыми системами. Предположим, что само параллельное существование и обоснование двух последних терминов - тому подтверждение. В государствах традиционно континентального права - все существеннее вес юридического / судебного прецедента (и да, мы снова об этом, актуальном для России явлении), в то время как в доктрине и практике других стран акты кодифицированного свойства укрепляют свой беспрекословно фундаментальный характер, хотя, в целом, роль судов [Makogon et al., 2018], правосудия как принципа [Kuksin et al., 2016] в государственно правовых механизмах, безусловно, можно оценивать как критичную, необходимую, но подчеркнуто недостаточную.

\section{Глобализация, право, сопряженные риски}

Факт влияния процессов глобализации на право в целом и на правовые системы в частности представляется очевидным. Последние в значительной мере и не всегда равнозначно сращиваются; активность лидирующего звена в этом процессе дает возможности для обособления общих директивных тенденций их эволюции. Среди таковых, к примеру, целесообразно выделить тенденцию к повышенному надзору за сферой обеспечения достойной жизнедеятельности личности [Butko et al., 2017], а также к формулированию принципов и обеспечению именно на их основе наиболее полной правовой поддержки потребностей человека [Новикова, 2007; Новикова, Жорник, 2012]; юридическое выражение признанных мировым сообществом принципов при отсутствии строгих оформленных критериев такого общемирового признания, что предполагает чрезмерную свободу, вольность для манипулятивного маневрирования; повышенное внимание к регулированию насущных и перспективных вопросов экологического направления; расширение и дробление сфер правового регулирования, обоснование, генезис и развитие ранее не сформированных и не обособившихся отраслей права (информационное право, право информационной безопасности, космическое право), которые, в то же время, несут признаки комплексных [Тонков, Синенко, 2016-а; 2016-б], и прочие не менее существенные тенденции.

Соответствующие качественные характеристики правовых систем государств, живя в переходном периоде, рвутся занять положение ориентиров глобализации и для глобализа- 
ции, и, следовательно, уместно говорить об их сближении по аналогии с естественнонаучными изысканиями по теории пределов. Наблюдаются процессы как формирования, так и разбалансировки относительно устойчивой системы, блоки которой (международное право, национальные правовые системы) видятся модулями, перманентно взаимодействуют, проявляют взаимную диффузию. В российской правовой доктрине до недавнего времени даже превалировала позиция, в соответствии с которой «в рамках указанной системы абсолютно оправдана и юридически допустима возможность вмешательства мирового сообщества во внутренние дела государства, где права и свободы человека не гарантируются или попросту нарушаются» [Тихомиров, Пиголкин, 2004]; без чрезмерных упрощений отмечалось, что, конечно, для этого необходимо заключение межгосударственных деяний насильственного (силового) характера, осуществляемых для поддержания мира, безопасности, поддержки института прав человека и т.д. в легитимные рамки, соответствующие международному праву, его нормам и, опять же, «общепризнанным» принципам.

Так же говоря о транснациональном принуждении, внимания через правовую призму заслуживают явления глобализирующейся, глобализировавшейся и глобальной преступности, детерминирующие угрозы для безопасности как феномена, так и частных ее ипостасей. В таком контексте показательными представляются как различные проявления транснациональной организованной преступной деятельности, в частности, международный терроризм, обнажающий протестные настроения [Мархгейм, 2016], вследствие недостаточной эффективности процесса и процессуального порядка управления, так и телеологические формы противодействия ей.

Из глобализации происходит пересмотр уголовно-правовой политики государств. Укрепление, расширение сотрудничества по противодействию именно открытому ряду преступлений декларируется «приоритетным» направлением этой политики. В стремлении обезопасить свое восхождение сильные могут, принося в жертву интересы вторых и третьих звеньев, оттягивать внимание от причин и условий рождений и взращивания, в данном случае, терроризма, оставляя исключительно властно-силовые пути предполагаемого решения проблемы названого «мирового зла».

Среди базов сфер отношений мы не усматриваем таких, которые не были бы подвержены критичному воздействию глобализации, требующей пересмотра установок о сущности и роли государства и права, их аксиологической и институциональной систем.

Правовая ныне грань процессов глобализации внешне остро выражается в «формировании новых юридических отношений, юридических институтов и норм» [Лукашук, 2000]. Как отмечает И.И. Лукашук, способствующая формированию глобальной правовой системы и генерирующая особые свойства в сфере правового влияния глобализация специфична по отношению к отдельным процессам, очевидно текущим в области базовой, социально-экономической, ведь единство в правовой материи далеко не всегда столь инерционно. По мнению автора, «государства в значительной мере сохраняют свою самостоятельность... Поэтому в отношении государств и их правовых систем более точен термин «интернационализация» [Лукашук, 2002].

Следовательно, суверенные государственно-правовые системы интегрируются с телами амбициозных транснациональных субъектов, передавая их организму часть элементов своего правового статуса, читай - свой исходный статус теряя.

При этом, конечно, может происходить избирательное взаимообогащение правовым опытом на паритетных началах, что, впрочем, ограничено [Makogon et al., 2019]. «Национальное право переходит на иной, более высший ли... а, быть может, нисходящий... но качественно новый уровень, на котором, действительно, зарождается своеобразная общемировая правовая система, чьи звенья связаны динамически и обоюдоостро; 
ген созидающего государства» [Борисов и др., 2016] в поисках путей выживания готов разрушать единицы соперничества. Как следствие - представления о флаге эталонных институтов национальной правовой системы нуждаются в переосмыслении, переоценке, и лучше - в формате ребилдинга (не путать с «перестройкой»), чего очевидно недостает перманентно переходному устройству. Для понимания, и учитывая трансрегиональный опыт научно-исследовательского поиска, последние уточнения считаем уместными.

Заметно, что именно в настоящее время глобализация лавинообразно усиливает взаимозависимость государств. Глобальная интеграция цепочек поставок, экономик в целом, фундаментализация влияния развитых стран существенно сузили возможности самостоятельного принятия справедливых и обоснованных решений. Не только нано-, но и попросту технологии кардинально расширили возможности коммуникации, анализа и обработки данных, информационного прессинга. Поэтому есть мнение, что «государство не должно больше принимать на себя обязанности единственного провайдера, а, скорее, выступать в роли помощника и регулятора. Рынки и граждане через самодеятельные и другие неправительственные организации стали требовать прозрачности и эффективности государственных институтов» [Тихомиров, Пиголкин, 2004].

Как утверждает М.В. Диас-Мелиан де Ханиш, классическая «концепция государственного суверенитета не совместима с существованием международного сообщества государств и международного публичного права, способного связать различные государства между собой» [Диас-Мелиан де Ханиш, 2001]. Автор говорит о полном пересмотре самой концепции государственного суверенитета, так как международные договоры каждый раз связывали более плотной сетью прав и обязанностей участников мирового сообщества; функционируют международные организации, уставы которых предполагают передачу им на договорной основе части государственного суверенитета [Диас-Мелиан де Ханиш, 2001].

Мир сам тянется к результатам успехов стран Запада. Но ведь мы уже находимся в том дне, когда субъектам, которым принадлежит «половина» мирового богатства, в логичном стремлении его сохранить приходится действовать с позиции силы. Отсюда проистекают и декларации о безусловном доминировании, «доктрина ста процентов» и пр. Мы не рассматриваем глобализацию как явление XXI века и считаем контрпродуктивным оставлять на задворках истории известное высказывание о том, что «если вы попробуете создать флот - мы нападем на вас».

Уже достаточное время наблюдается быстрая эволюция международных структур, возникновение и функционирование новых систем, что позволяет говорить о всевозрастающих интеграционных процессах на почве глобализации, являющихся результатом признания взаимозависимости и взаимодействия государств. Такова общая природа интеграции. Любой интеграционный процесс непременно сопровождается системой правил, необходимых для постановки целей и его организации, а процесс интеграции между двумя или более странами - тем более регулируется объективно необходимым в современном обществе комплексом юридических норм и принципов.

Таким образом, мировые интеграционные процессы неизбежно влекут интеграцию правовую, которую с некоторой долей условности действительно можно определить как процесс формирования новой, общемировой системы норм, организующих и обеспечивающих глобальное межгосударственное взаимодействие и взаимопроникновение во всех четырех сферах жизни социума. Характер правовой интеграции определяется, с одной стороны, участием государств в делах мирового сообщества, а с другой - степенью восприятия странами тех или иных правовых ценностей и достижений государств и их семей.

Правовые семьи суверенных государств сближаются как объективно, так и целенаправленно, интегрируясь друг в друга и признавая нормы международного права. Уже со- 
здан правовой мир, место глобализации в котором никак нельзя обозначить ролью второго плана и уж тем более - декорациями.

\section{Заключение}

На основании положений представленного исследования считаем возможным сформулировать определение правовой глобализации, отметив его блочно-модульный конструктив.

Правовая глобализация - это процесс, объективно порождаемый общей глобализацией, влекущий формирование и общемировое признание гармонизированных и унифицированных правовых принципов, норм, а также правовых теорий, катализирующий взаимовлияние и взаимопроникновение национального права государств добровольно либо вследствие опосредованного последовательного навязывания.

\section{Список литературы}

1. Борисов Г.А., Комаров И.М., Кучин О.С., Мархгейм М.В., Нифанов А.Н., Новикова А.Е., Носков В.А., Тонков Е.Е. 2016. Государство созидающее: юридическая модель и современные риски. Сер. Теория и история государства и права. М., 416 с.

2. Тихомиров Ю.А., Пиголкин А.С. 2004. Глобализация и развитие законодательства: Очерки. М., 464 с.

3. Лукашук И.И. 2002. Взаимодействие международного и внутригосударственного права в условиях глобализации. Журнал российского права, 3: 115-128.

4. Лукашук И.И. 2000. Глобализация, государство, право, XXI век. М., 279 с.

5. М.В. Диас-Мелиан де Ханиш. 2001. Основы и природа правовой интеграции. Правоведение, 6: 173-178.

6. Мархгейм М.В. 2016. Право на протест: конституционный абрис собирательного образа. Наука и образование: хозяйство и экономика; предпринимательство; право и управление, 3: 29-31.

7. Новикова А.Е., Анисимов А.П. 2008. Экологические правозащитные риски: проблемы теории и практики. Адвокатская практика, 4: 5-7.

8. Новикова А.Е., Жорник А.М. 2012. Генезис и содержание института политического убежища в Российской Федерации. Научные ведомости Белгородского государственного университета. Серия: Философия. Социология. Право, 20 (139): 163-169.

9. Новикова А.Е. 2007. Институт уполномоченного по правам человека в Российской Федерации (историко-правовой и теоретико-правовой аспекты): Автореф. дис. ... канд. юрид. наук. СПб., 22 с.

10. Тонков Е.Е., Синенко В.С. 2016-а. Комплексные отрасли права: плодотворная идея или отказ от формальной определенности в правовой науке? Вестник Воронежского государственного университета. Серия: Право, 2 (25): 53-75.

11. Тонков Е.Е., Синенко В.С. 2016-б. Комплексные отрасли в системе права и системе законодательства. Журнал российского права, 11 (239): 5-12.

12. Butko L.V., Markhgeym M.V., Novikova A.E., Pozharova L.A., Tonkov E.E. 2017. Personal Dignity in the European Legal Culture. Journal of History Culture and Art Research, 6 (4): 296-303.

13. Kornyushkina A.Y., Markhgeym M.V., Novikova A.E., Doronina O.N., Zajcev S.Y. 2017. Minimization of human rights risks: the constitutional legal experience of post-soviet states. Turkish online journal of design art and communication, 7 (S-APRLSPCL): 352-356.

14. Kuksin I.N., Markhgeym M.V., Novikova A.E., Tonkov E.E. 2016. Justice as principle: aspects of genesis in social and regulatory systems. The Social Sciences (Pakistan), 11 (10): 2367-2370.

15. Makogon B.V., Markhgeym M.V., Minasyan A.A., Novikova A.E., Yarychev N.U. 2019. Logical classification of legal procedural restrictions. Revista Inclusiones, 6 (S2-5): 395-401.

16. Makogon B.V., Markhgeym M.V., Novikova A.E., Nikonova L.I., Stus N.V. 2018. Constitutional Justice in Circumstances of Public Authority Limits. Journal of History Culture and Art Research, 7 (2): 722-728. 


\section{References}

1. Borisov G.A., Komarov I.M., Kuchin O.S., Markhgeym M.V., Nifanov A.N., Novikova A.E., Noskov V.A., Tonkov E.E. 2016. Gosudarstvo sozidajushhee: juridicheskaja model' i sovremennye riski. [The creative state: the legal model and modern risks]. Ser. Teorija i istorija gosudarstva i prava. M., 416 p.

2. Tihomirov Ju.A., Pigolkin A.S. 2004. Globalizacija i razvitie zakonodatel'stva: Ocherki. [Globalization and development of legislation: Essays]. M., 464 p. (in Russian)

3. Lukashuk I.I. 2002. Vzaimodejstvie mezhdunarodnogo i vnutrigosudarstvennogo prava v uslovijah globalizacii. [Interaction of international and domestic law in the context of globalization]. Zhurnal rossijskogo prava, 3: 115-128. (in Russian)

4. Lukashuk I.I. 2000. Globalizacija, gosudarstvo, pravo, XXI vek. [Globalization, state, law, the XXI century]. M., 279 p. (in Russian)

5. M.V. Dias-Melian de Hanish. 2001. Osnovy i priroda pravovoj integracii. [Fundamentals and nature of legal integration]. Pravovedenie, 6: 173-178. (in Russian)

6. Markhgeym M.V. 2016. Pravo na protest: konstitucionnyj abris sobiratel'nogo obraza. [The right to protest: the constitutional outline of a collective image]. Nauka i obrazovanie: hozjajstvo i jekonomika; predprinimatel'stvo; pravo i upravlenie, 3: 29-31. (in Russian)

7. Novikova A.E., Anisimov A.P. 2008. Jekologicheskie pravozashhitnye riski: problemy teorii i praktiki. [Environmental human rights risks: problems of theory and practice]. Advokatskaja praktika, 4: 5-7.

8. Novikova A.E., Zhornik A.M. 2012. Genezis i soderzhanie instituta politicheskogo ubezhishha v Rossijskoj Federacii. [Genesis and content of the institution of political asylum in the Russian Federation]. Nauchnye vedomosti Belgorodskogo gosudarstvennogo universiteta. Serija: Filosofija. Sociologija. Pravo, 20 (139): 163-169. (in Russian)

9. Novikova A.E. 2007. Institut upolnomochennogo po pravam cheloveka v Rossijskoj Federacii (istoriko-pravovoj i teoretiko-pravovoj aspekty): Avtoref. dis. ... kand. jurid. nauk. [Institute of the Commissioner for human rights in the Russian Federation (historical-legal and theoretical-legal aspects): Autoref. dis. ... Cand. of legal sciences]. SPb., 22 p. (in Russian)

10. Tonkov E.E., Sinenko V.S. 2016. Kompleksnye otrasli prava: plodotvornaja ideja ili otkaz ot formal'noj opredelennosti v pravovoj nauke? [Complex branches of law: a fruitful idea or a rejection of formal certainty in legal science?]. Vestnik Voronezhskogo gosudarstvennogo universiteta. Serija: Pravo, 2 (25): 53-75 (in Russian)

11. Tonkov E.E., Sinenko V.S. (2) 2016. Kompleksnye otrasli v sisteme prava i sisteme zakonodatel'stva. [Complex industries in the system of law and legislation]. Zhurnal rossijskogo prava, 11 (239): 5-12. (in Russian)

12. Butko L.V., Markhgeym M.V., Novikova A.E., Pozharova L.A., Tonkov E.E. 2017. Personal Dignity in the European Legal Culture. Journal of History Culture and Art Research, 6. (4): 296-303.

13. Kornyushkina A.Y., Markhgeym M.V., Novikova A.E., Doronina O.N., Zajcev S.Y. 2017. Minimization of human rights risks: the constitutional legal experience of post-soviet states. Turkish online journal of design art and communication, 7 (S-APRLSPCL): 352-356.

14. Kuksin I.N., Markhgeym M.V., Novikova A.E., Tonkov E.E. 2016. Justice as principle: aspects of genesis in social and regulatory systems. The Social Sciences (Pakistan), 11(10): 2367-2370.

15. Makogon B.V., Markhgeym M.V., Minasyan A.A., Novikova A.E., Yarychev N.U. 2019. Logical classification of legal procedural restrictions. Revista Inclusiones, 6 (S2-5): 395-401.

16. Makogon B.V., Markhgeym M.V., Novikova A.E., Nikonova L.I., Stus N.V. 2018. Constitutional Justice in Circumstances of Public Authority Limits. Journal of History Culture and Art Research, 7 (2): 722-728.

\section{ИНФОРМАЦИЯ ОБ АВТОРЕ}

Макогон Борис Валерьевич, доктор юридических наук, доцент, доцент кафедры конституционного и международного права Белгородского государственного национального исследовательского университета, Белгород, Россия

\section{INFORMATION ABOUT THE AUTHOR}

Makogon Boris Valer'evich, doctor of law, associate Professor, associate Professor of the Department of constitutional and international law of the Belgorod National Research University, Belgorod, Russia 